\title{
COMPARISON OF THIOPENTONE (1.25\%) AND PROPOFOL (1\%) FOR INSERTION OF LARYNGEAL MASK AIRWAY IN PAEDIATRIC PATIENTS
}

\author{
Bhavna Royzada1, Avijit Royzada², Durga Kosam³, Madhumita G. Murthy ${ }^{4}$
}

${ }^{1}$ Associate Professor, Department of Anaesthesia, Chhattisgarh Institute of Medical Sciences, Bilaspur, Chhattisgarh, India.

2Director, Saibaba Hospital, Bilaspur, Chhattisgarh, India.

${ }^{3}$ Associate Professor, Department of Anaesthesia, Chhattisgarh Institute of Medical Sciences, Bilaspur, Chhattisgarh, India. ${ }^{4}$ Professor, Department of Anaesthesia, Chhattisgarh Institute of Medical Sciences, Bilaspur, Chhattisgarh, India.

ABSTRACT
BACKGROUND
Laryngeal mask airway is widely used in management of paediatric anaesthesia. This study has been designed to investigate
whether Propofol $1 \%$ alone or Thiopentone along with Halothane is suitable agent for LMA insertion in relation to ease of
insertion, pain on injection, haemodynamic instability and recovery in children.

\section{MATERIALS AND METHODS}

In this randomized double-blind prospective study, 50 ASA grade I \& II patients of age 3 to 5 years were included. Patients were divided into two groups: P group received Propofol 1\%, $3.5 \mathrm{mg} / \mathrm{kg}$ and T group received Thiopentone $1.25 \%, 5 \mathrm{mg} / \mathrm{kg}$ along with Halothane. All children were evaluated for ease of insertion, pain on injection, jaw relaxation, coughing, gagging, involuntary limb movements, recovery and haemodynamic stability.

\section{RESULTS}

Propofol group had $96 \%$ single attempt insertion of LMA as compared to $(76 \%)$ in Thiopentone group ( $\mathrm{P}<0.5)$, mean score for Jaw relaxation was 3 in propofol group whereas in Thiopentone group it was $2.6(\mathrm{P}<0.5)$. Shivalingum score for incidence of adverse responses to airway manipulation, such as coughing, gagging, laryngospasm, limb movements were $17.96 \pm 0.2$ in Propofol group and $13.84 \pm 0.2$ in Thiopentone group $(\mathrm{P}<0.5)$, systolic blood pressure after 1 minute of LMA insertion was $118.72 \pm 2.71$ with propofol group whereas it was $125.52 \pm 3.45$ in Thiopentone group $(\mathrm{P}<0.5)$

\section{CONCLUSION}

Propofol has smooth induction, haemodynamic stability and smooth recovery characteristics with less postoperative complications in children.

\section{KEY WORDS}

Propofol, Thiopentone, Laryngeal Mask Airway, Paediatric.

HOW TO CITE THIS ARTICLE: Royzada B, Royzada A, Kosam D, et al. Comparison of thiopentone (1.25\%) and propofol (1\%) for insertion of laryngeal mask airway in paediatric patients. J. Evolution Med. Dent. Sci. 2019;8(03):211-216, D0I: $10.14260 /$ jemds/2019/46

\section{BACKGROUND}

The Laryngeal mask airway has been widely used in paediatric patients ${ }^{1}$. There are fewer hypoxic episodes with LMA than with face mask. The LMA has been used in paediatric difficult airway and neonatal resuscitation. Experience in adults is essential before attempting utilization of LMA in paediatric patients. We planned this study with a view to compare the effects of Thiopentone \& Propofol on ease of insertion of LMA, haemodynamic stability and recovery in paediatric patients.

\section{MATERIALS \& METHODS}

Total 50 children belonging to ASA grade I \& II, belonging to either sex, hence we select 25 samples in both groups. A study design was undertaken as double-blind randomized control trails (RCT).

'Financial or Other Competing Interest': None.

Submission 08-12-2018, Peer Review 06-02-2019,

Acceptance 12-01-2019, Published 21-01-2019.

Corresponding Author:

Dr. Bhavna Royzada,

Saibaba Hospital,

Gaurav Path, Bilaspur, Chhattisgarh, India.

E-mail: bhavnathegreat@yahoo.co.in

DOI: $10.14260 /$ jemds $/ 2019 / 46$
Study was undertaken with 50 children belonging to ASA grade I \& II, belonging to either sex, of age 3-5 years weighing between 10-20 Kg undergoing elective surgeries of short duration like Herniotomy, Orchidopexy, Cystolithotomy. Orthopaedic operations like CTEV. Duration of surgery was 30-60 minutes. ${ }^{2,3,4}$ The patients were randomly selected by lottery method into two groups of 25 children in each group. Informed consent was taken from all the patients. Sample size taken for convenience.

Thorough pre-anaesthetic checkup was done with detailed clinical history and examination and routine investigations was carried out. Patients were not taken up if they required surgeries in non-supine positions and not fasting. Patients with subglottic airway obstruction, allergy to either agent, limited mouth opening, palatal defects, oropharyngeal masses and also patients having sore throat were not included in the study. Randomisation was carried out in a 1:1 ratio with the aid of a computer-generated random process with concealment. Patients were randomly divided into both groups in a double-blind manner the randomization allotted to the patients and were blinded to it until the study was completed. 5,6 This ensured the double blinding. Different concentrations $(0.75 \%$ and $0.5 \%)$ were covered with opaque sacks by the pharmacist in the 1:1 ratio. Only the pharmacist was aware of the code given to the type of solution in the vials. This ensured the double blinding. 


\section{Statistical Analysis}

All results are expressed in mean and SD. Data was analysed using Microsoft excel and SPSS software version 17. Suitable statistical tests like Chi square test and unpaired test were used to analyse the data. A p value of less than 0.05 was considered statistically significant. Incidence of adverse response to airway manipulation, such as coughing, gagging, laryngospasm, jaw relaxation, limb movement and ease of insertion was analysed using the Chi square test with Fisher exact test.

\section{RESULTS}

Present study was conducted with 50 patients of ASA grade I and II in the age group of 3-5 years undergoing various elective surgical procedures. Demographic data was comparable in both the group.

\section{Sivalingum Score}

\begin{tabular}{|c|c|c|c|}
\hline \multirow{2}{*}{ Variables } & \multicolumn{3}{|c|}{ Points } \\
\cline { 2 - 4 } & $\mathbf{3}$ & $\mathbf{2}$ & $\mathbf{1}$ \\
\hline 1. Jaw Opening & Full & Partial & Nil \\
\hline 2. Ease of LMA Inserting & Easy & Difficult & Impossible \\
\hline 3. Coughing & Nil & + & ++ \\
\hline 4. Gagging & Nil & + & ++ \\
\hline $\begin{array}{c}\text { 5. Laryngospasm/Airway } \\
\text { Obstruction }\end{array}$ & Nil & Partial & Total \\
\hline 6. Movements & Nil & Moderate & Vigorous \\
\hline \multicolumn{3}{|c}{ Table 1 } \\
\hline
\end{tabular}

Score of 18 was considered excellent.

18-15 was good.

$15-12$ as satisfactory.

Below 12 as poor.

Pules, BP, SpO2, ETCO2 \& ECG were recorded after induction, after LMA insertion, $1 \mathrm{~min}, 2 \mathrm{~min}, 3 \mathrm{~min}, 4 \mathrm{~min}, \& 5$ min after insertion of LMA.

Number of attempts required for LMA insertion were noted in all patients. After two unsuccessful attempts LMA was abandoned and patients were intubated with succinyl choline.

After insertion \& confirming the proper placement of LMA, anaesthesia was maintained with Halothane \& $\mathrm{N}_{2} \mathrm{O}: \mathrm{O}_{2}$ (50:50\%) patients were kept on spontaneous ventilation using Jackson Rees circuit. Vitals were recorded every 5 minutes. Respiratory rate was monitored by observing tidal excursions in the reservoir bag. After completion of surgery LMA was removed when the patients were fully awake. Patients were observed for 24 hours postoperatively for complications if any like regurgitation, aspiration, sore throat, dysphagia, dysarthria, injuries to glottis \& other soft tissues, various nerve injuries and parotid gland swelling. Patients were premedicated with intravenous Glycopyrronium bromide $0.005 \mathrm{mg} / \mathrm{kg}$ body weight.

\section{Children were divided in Two Group of 25 Children each-}

- Group T received Thiopentone sodium $1.25 \%, 5 \mathrm{mg} / \mathrm{kg}$ along with Halothane ${ }^{7}$

- Group P received Propofol 1\%, $3.5 \mathrm{mg} / \mathrm{kg}$ for induction.
After securing patent venous access, pulse and blood pressure of all the patients were taken and monitors were attached viz. pulse oximeter, ETCO2 monitor and ECG for baseline values.

Pulse \& blood pressure of all the patient were recorded again after premedication with glycopyrrolate. All patients received $100 \%$ oxygen soon after premedication.

Group $\mathrm{T}$ received Inj. Thiopentone sodium $1.25 \%, 5$ $\mathrm{mg} / \mathrm{kg}$ along with Halothane as required

Group $\mathrm{P}$ received Inj. Propofol 1\%, $3.5 \mathrm{mg} / \mathrm{kg}$ for induction over 30 seconds.

Size \# 2 LMA which was tested for any leaks etc. before introduction was well lubricated on posterior side with $2 \%$ Lignocaine jelly. Adequate jaw relaxation was assessed \& LMA was introduced with the cuff partially inflated. $\mathbf{8 , 9}$

Correct placement of LMA was verified by auscultation of respiratory sounds, chest movements, anterior movement of larynx, and outward movement of LMA on cuff inflation, black line on LMA facing upper lip in midline, movement of reservoir bag with spontaneous breathing, ability to ventilate manually. Proper placement of LMA was confirmed \& then cuff was inflated with air in all cases. Response to insertion of LMA was graded on a 18 point scale suggested by Sivalingum et al. (1999)

\begin{tabular}{|c|c|c|}
\hline & Group T & Group P \\
\hline Age in Years & $4 \pm 0.76$ & $3.88 \pm 0.72$ \\
\hline Weight in Kgs. & $12.39 \pm 2.03$ & $15.48 \pm 1.86$ \\
\hline \multicolumn{3}{|c|}{ Table 2. Mean \& SD Of Age and Weight of Children } \\
\hline
\end{tabular}

Above table shows there were no statistically significant differences among both the groups with respect to age and weight.

\begin{tabular}{|c|c|c|c|c|c|}
\hline \multirow{2}{*}{$\begin{array}{c}\text { Sr. } \\
\text { No. }\end{array}$} & \multirow{2}{*}{ Sex } & \multicolumn{2}{|c|}{ Group T } & \multicolumn{2}{c|}{ Group P } \\
\cline { 3 - 6 } & $\begin{array}{c}\text { No. of } \\
\text { Cases }\end{array}$ & Percentage & $\begin{array}{c}\text { No. of } \\
\text { Cases }\end{array}$ & Percentage \\
\hline 1 & Male & 20 & $80 \%$ & 20 & $80 \%$ \\
\hline 2 & Female & 5 & $20 \%$ & 5 & $20 \%$ \\
\hline \multicolumn{3}{|c|}{ Table 3. Distribution of Children According to Sex } \\
\hline
\end{tabular}

Male female ratio was maintained in both the groups.

\begin{tabular}{|c|c|c|}
\hline Duration of Surgery & Group T & Group P \\
\hline Mean (Minutes) & 43.6 & 44.4 \\
\hline \pm SD & \pm 8.55 & \pm 7.05 \\
\hline \multicolumn{2}{|c|}{ Table 4. Mean Duration of Surgery } \\
\hline
\end{tabular}

Duration of surgery was comparable and less than 1-hour duration in both the groups.

\begin{tabular}{|c|c|c|}
\hline Attempts & Group T & Group P \\
\hline Once & $19(76 \%)$ & $24(96 \%)$ \\
\hline Twice & $04(16 \%)$ & $01(4 \%)$ \\
\hline Abandoned & $02(8 \%)$ & 0 \\
\hline Table 5. Showing Number of Attempts for LMA Insertion \\
\hline
\end{tabular}

It is clear that Propofol has better single attempt insertion rate. 


\begin{tabular}{|c|c|c|c|}
\hline Group & Additional Dose & No. of Patients & Percentage \\
\hline Group T & Yes & 4 & $16 \%$ \\
\hline Group P & No & 0 & $0 \%$ \\
\hline \multicolumn{2}{|c|}{ Table 6. Requirement of Additional Doses } \\
\hline
\end{tabular}

No patient in Propofol group required additional doses.

\begin{tabular}{|c|c|c|c|c|}
\hline Sr. No. & Response & Group T & Group P & 'P' Value \\
\hline 01 & Jaw relaxation & 2.60 & 3 & $<0.05$ \\
\hline 02 & Ease of inserting & 2.12 & 3 & $<0.05$ \\
\hline 03 & Gagging & 2.24 & 3 & $<0.05$ \\
\hline 04 & Coughing & 2.28 & 3 & $<0.05$ \\
\hline 05 & Laryngospasm & 2.48 & 3 & $<0.05$ \\
\hline 06 & Limb Movements & 2.04 & 2.96 & $<0.05$ \\
\hline \multicolumn{4}{|c|}{ Table 7. Mean Response to Laryngeal Mask Airway Insertion } \\
\hline
\end{tabular}

\begin{tabular}{|l|c|}
\hline Groups & Total Score \\
\hline Group T & $13.84 \pm 2.2$ \\
\hline Group P & $17.96 \pm 0.2$ \\
\hline \multicolumn{2}{|c|}{ Table 8. Showing Mean Total Score in Both the Groups } \\
\hline \multicolumn{2}{|c|}{}
\end{tabular}

The incidence of adverse responses to airway manipulation, such as coughing, gagging, laryngospasm, involuntary limb movement were less in Propofol group.

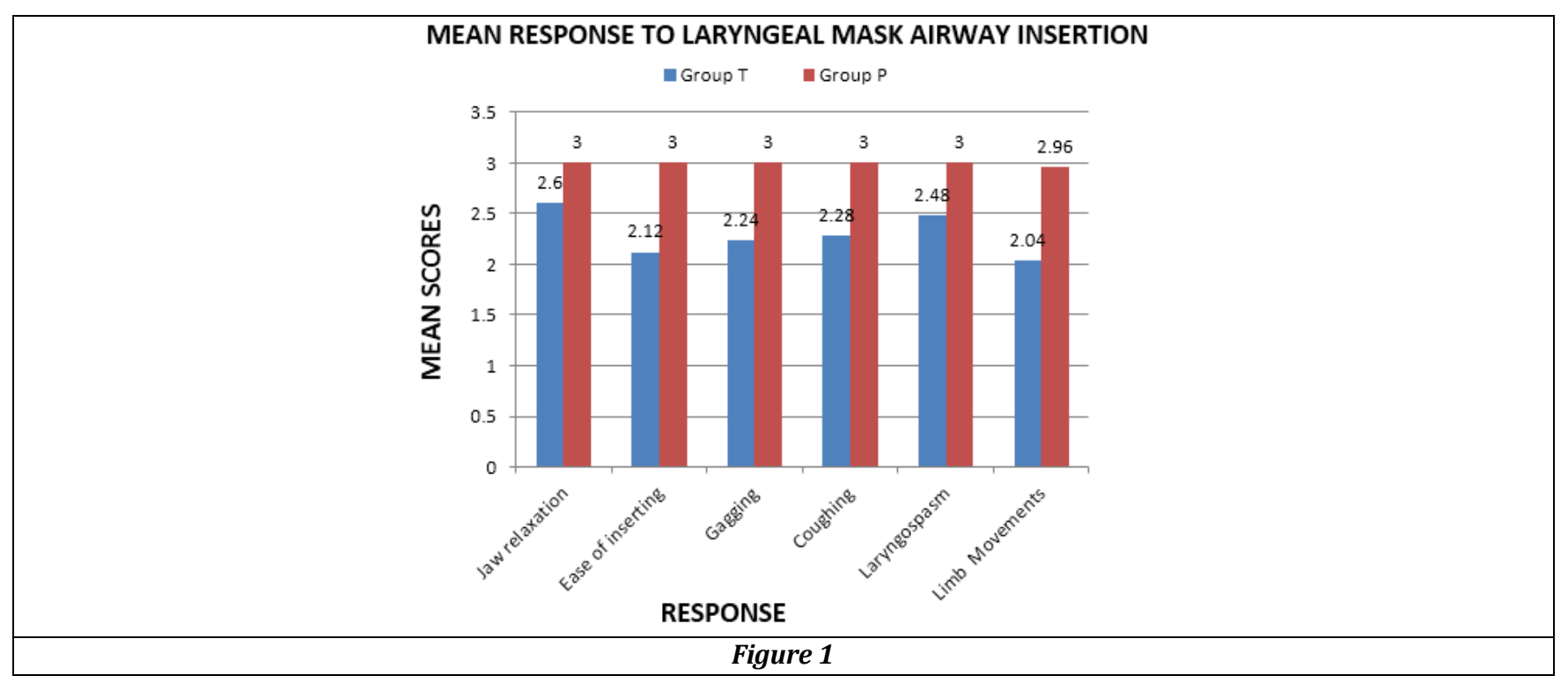

There was rise in pulse rate after induction and it was maximum after 1 minute of LMA insertion in both the groups but with group $\mathrm{P}$ rise in pulse rate was less than Thiopentone, it was significant $(\mathrm{p}<0.05)$ afterwards pulse rate declined \& came to near preinduction values in group $\mathrm{P}$ whereas in Group Tit was much higher than preinduction levels $(\mathrm{p}<0.05)$.

\begin{tabular}{|c|c|c|c|c|c|c|}
\hline Hemodynamic Variable & \multicolumn{3}{|c|}{ Group T } & \multicolumn{2}{|c|}{ Group P } & p-Value \\
\hline \multirow{2}{*}{ Basal Pulse Rate } & Mean & 96.96 & \multirow{2}{*}{$0 \%$} & 99.92 & \multirow{2}{*}{$0 \%$} & \multirow{2}{*}{$>0.05$} \\
\hline & SD & 5.03 & & 4.61 & & \\
\hline \multirow{2}{*}{ After Premedication } & Mean & 99.6 & \multirow{2}{*}{$2.72 \%$} & 101.92 & \multirow{2}{*}{$2 \%$} & \multirow{2}{*}{$>0.05$} \\
\hline & SD & 4.35 & & 4.33 & & \\
\hline \multirow{2}{*}{ After Induction } & Mean & 108 & \multirow{2}{*}{$11.38 \%$} & 105.36 & \multirow{2}{*}{$5.44 \%$} & \multirow{2}{*}{$>0.05$} \\
\hline & SD & 4.11 & & 4.66 & & \\
\hline \multirow{2}{*}{ After LMA Insertion } & Mean & 114 & \multirow{2}{*}{$17.57 \%$} & 106.72 & \multirow{2}{*}{$6.8 \%$} & \multirow{2}{*}{$<0.05$} \\
\hline & SD & 4.54 & & 4.19 & & \\
\hline \multirow{2}{*}{ After 1 Min } & Mean & 122.4 & \multirow{2}{*}{$26.23 \%$} & 108.16 & \multirow{2}{*}{$8.24 \%$} & \multirow{2}{*}{$<0.05$} \\
\hline & SD & 2.47 & & 4.52 & & \\
\hline \multirow{2}{*}{ After 2 Min } & Mean & 117.52 & \multirow{2}{*}{$21.70 \%$} & 107.04 & \multirow{2}{*}{$7.12 \%$} & \multirow{2}{*}{$<0.05$} \\
\hline & SD & 2.48 & & 4.04 & & \\
\hline \multirow{2}{*}{ After 3 Min } & Mean & 113.84 & \multirow{2}{*}{$17.40 \%$} & 106 & \multirow{2}{*}{$6 \%$} & \multirow{2}{*}{$<0.05$} \\
\hline & SD & 2.71 & & 3.3 & & \\
\hline
\end{tabular}




\begin{tabular}{|c|c|c|c|c|c|c|}
\hline \multirow[b]{2}{*}{ After 4 Min } & Mean & 108.4 & \multirow[b]{2}{*}{$11.79 \%$} & 104.32 & \multirow[b]{2}{*}{$4.40 \%$} & \multirow[b]{2}{*}{$<0.05$} \\
\hline & SD & 3.10 & & 2.63 & & \\
\hline \multirow{2}{*}{ After 5 Min } & Mean & 103.04 & \multirow{2}{*}{$6.27 \%$} & 103.04 & \multirow{2}{*}{$3.12 \%$} & \multirow{2}{*}{$<0.05$} \\
\hline & SD & 4.63 & & 2.13 & & \\
\hline
\end{tabular}

\begin{tabular}{|c|c|c|c|c|c|c|}
\hline Hemodynamic Variable & & Group T & & & & P Value \\
\hline \multirow{2}{*}{ Basal SBP } & Mean & 111.84 & \multirow{2}{*}{$0 \%$} & 113.28 & \multirow{2}{*}{$0 \%$} & \multirow{2}{*}{$>0.05$} \\
\hline & SD & 5.65 & & 4.86 & & \\
\hline \multirow{2}{*}{ After Premedication } & Mean & 112.78 & \multirow{2}{*}{$0.08 \%$} & 114.8 & \multirow{2}{*}{$1.4 \%$} & \multirow{2}{*}{$>0.05$} \\
\hline & SD & 5.78 & & 3.84 & & \\
\hline \multirow{2}{*}{ After induction } & Mean & 114.5 & \multirow{2}{*}{$2.37 \%$} & 109.28 & \multirow{2}{*}{$-9.64 \%$} & \multirow{2}{*}{$<0.05$} \\
\hline & SD & 4.64 & & 4.49 & & \\
\hline \multirow{2}{*}{ After LMA Insertion } & Mean & 120.4 & \multirow{2}{*}{$7.65 \%$} & 117.36 & \multirow{2}{*}{$3.88 \%$} & \multirow{2}{*}{$<0.05$} \\
\hline & SD & 4.23 & & 3.28 & & \\
\hline \multirow{2}{*}{ After 1 Min } & Mean & 125.52 & \multirow{2}{*}{$12.23 \%$} & 118.72 & \multirow{2}{*}{$4.8 \%$} & \multirow{2}{*}{$<0.05$} \\
\hline & SD & 3.45 & & 2.71 & & \\
\hline \multirow{2}{*}{ After 2 Min } & Mean & 122.48 & \multirow{2}{*}{$9.57 \%$} & 118 & \multirow{2}{*}{$4.16 \%$} & \multirow{2}{*}{$<0.05$} \\
\hline & SD & 3.16 & & 2.71 & & \\
\hline \multirow{2}{*}{ After 3 Min } & Mean & 119.44 & \multirow[b]{2}{*}{$6.79 \%$} & 117.28 & \multirow{2}{*}{$3.55 \%$} & \multirow{2}{*}{$<0.05$} \\
\hline & SD & 3.23 & & 2.71 & & \\
\hline \multirow{2}{*}{ After 4 Min } & Mean & 117.44 & \multirow{2}{*}{$5.0 \%$} & 116.24 & \multirow{2}{*}{$2.16 \%$} & \multirow{2}{*}{$<0.05$} \\
\hline & SD & 3.98 & & 2.73 & & \\
\hline \multirow{2}{*}{ After 5 Min } & Mean & 115.68 & \multirow{2}{*}{$3.61 \%$} & 115.52 & \multirow{2}{*}{$1.97 \%$} & \multirow{2}{*}{$<0.05$} \\
\hline & SD & 4.55 & & 2.95 & & \\
\hline
\end{tabular}

Table 10. Mean \pm SD of Systolic Blood Pressure (SBP) in mmHg Recorded at Different Time Intervals in Both The Groups

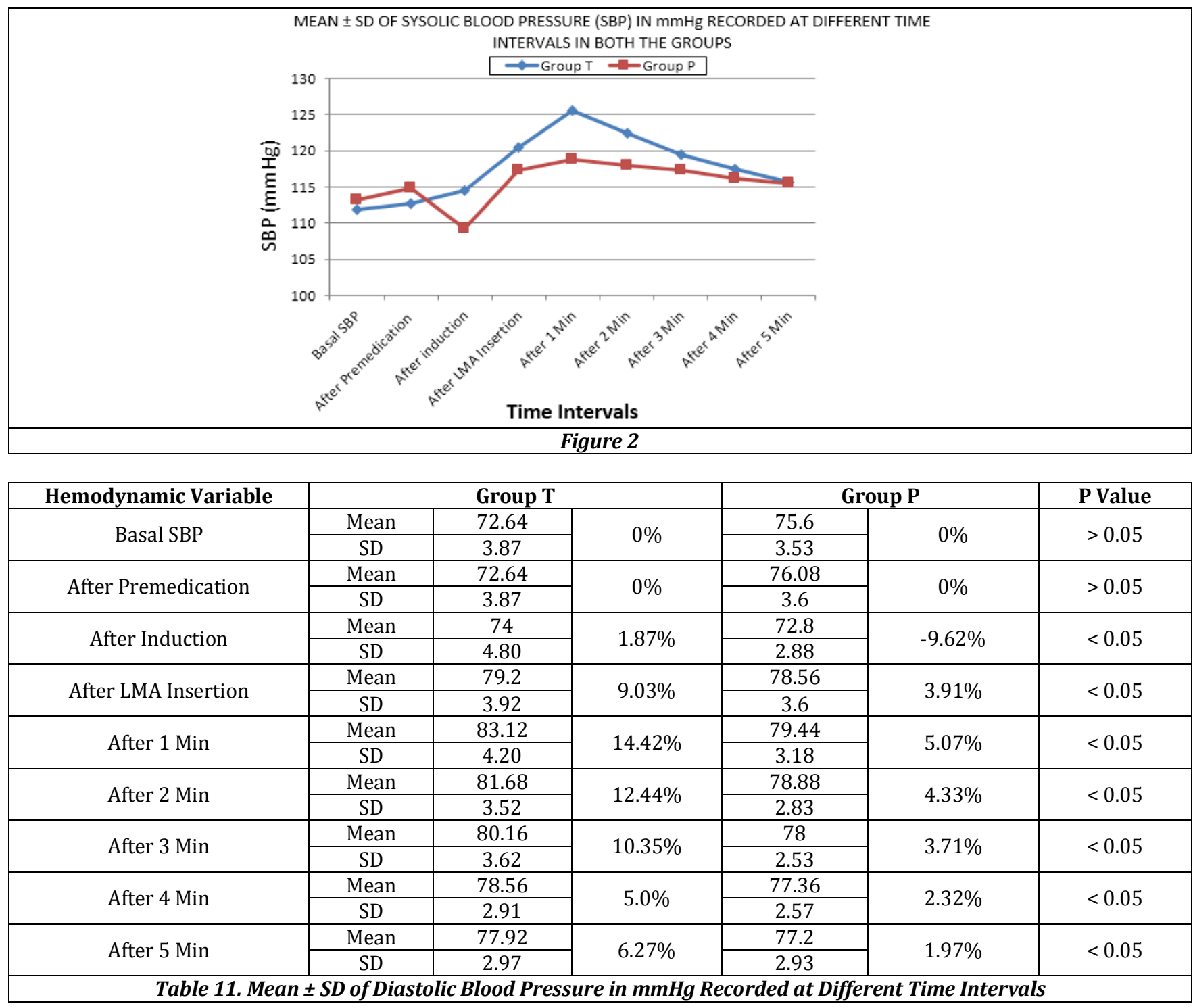




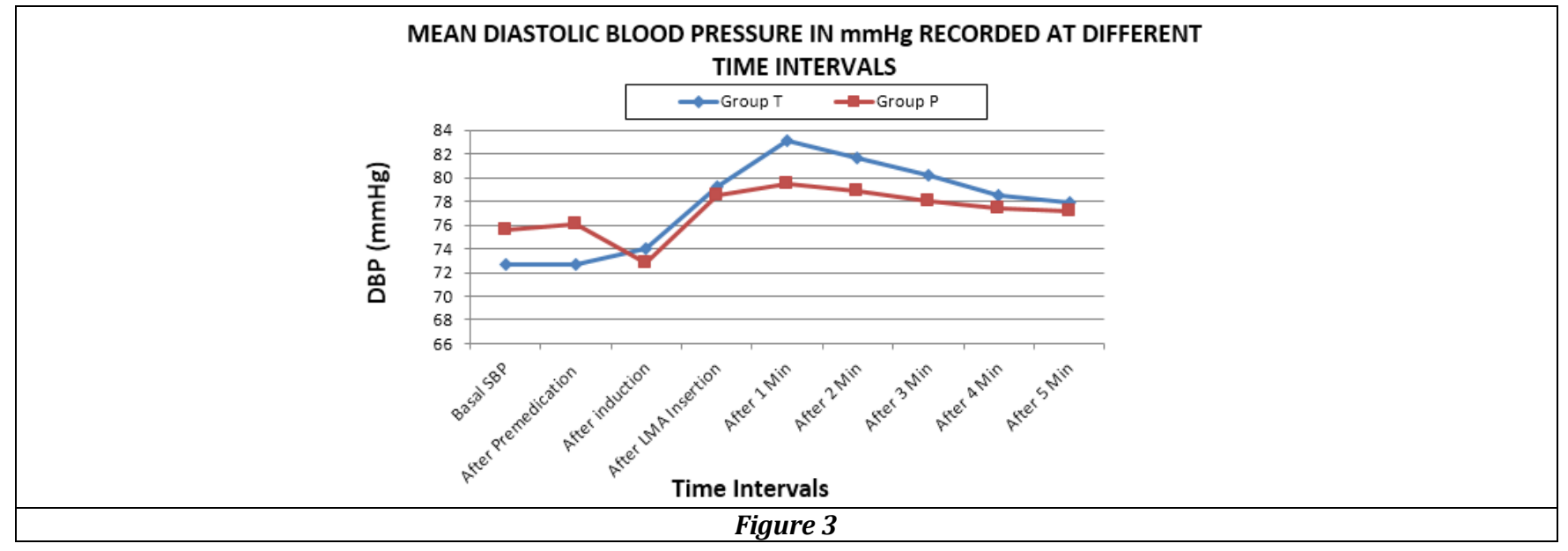

There was rise in systolic as well as diastolic blood pressure after induction with Thiopentone. This rise peaked after 1 min. of LMA insertion and was much higher than preinduction levels even after 5 mins. Of LMA insertion $(\mathrm{P}<0.05)$ in group $\mathrm{T}$.

\begin{tabular}{|c|c|c|}
\hline Complications & Group T & Group P \\
\hline Regurgitation (After LMA removal) & $2(8 \%)$ & $1(4 \%)$ \\
\hline Aspiration & 0 & 0 \\
\hline Sore throat & $1(4 \%)$ & $1(4 \%)$ \\
\hline Dysphagia & 0 & 0 \\
\hline Dysarthria & 0 & 0 \\
\hline Nerve Injury & 0 & 0 \\
\hline Soft Tissue Injury & 0 & 0 \\
\hline \multicolumn{2}{|c|}{ Table 12. Postoperative Complications } \\
\hline
\end{tabular}

Postoperative complications were comparable in both the groups. 10

\section{DISCUSSION}

The Laryngeal mask airway provides a direct connection to the tracheal airway without the need of laryngoscopy and tracheal intubation. There is less incidence of arterial desaturation, less airway stimulation and liberation of anaesthetist to attend to other responsibilities.

Successful LMA insertion requires an adequate depth of anaesthesia by use of either inhalational or intravenous agents to suppress pharyngeal and laryngeal reflexes

Propofol provides rapid induction with excellent jaw relaxation, but has disadvantage as pain at injection site, involuntary limb movements, prolonged apnoea \& hypotension. ${ }^{11,12}$

Thiopentone has advantages of painless injection and less hypotension although it does not provide good jaw relaxation and can cause coughing, gagging and laryngospasm when used alone for LMA insertion. It has been used with topical lidocaine spray, or co-induction with Midazolam or Halothane.

Age of children selected was above 3 years as use of propofol is not recommended below this age. (Manufacturers of Diprivan Astra Zeneca 1993).

Use of additional induction agent was significantly greater in Thiopentone group. No patient in Propofol group required additional doses.

After two unsuccessful attempts LMA was abandoned \& patients were intubated with succinylcholine.

Response to insertion of LMA was graded on 18-point scale suggested by P. Sivalingum et al. (1999), ${ }^{13}$ jaw relaxation, ease of insertion, gagging, coughing, laryngospasm and limb movements were noted \& graded as excellent, good, satisfactory\& poor for insertion of LMA Mean total score was good with Propofol and it was statistically significant $(<0.05) \cdot{ }^{14}$

LMA was inserted in single attempt in $96 \%$ cases with Propofol whereas with Thiopentone $76 \%$ patients achieved single attempt insertion. $8 \%$ cases required abandonment of LMA in Thiopentone group, no such cases were noted with propofol.

For assessing haemodynamic response to LMA insertion pulse rate and blood pressure of the patient were noted after induction, after LMA insertion, $1 \mathrm{~min}, 2 \mathrm{~min}, 3 \mathrm{~min}, 4 \mathrm{~min} \& 5$ min after insertion. ${ }^{15}$

There were less haemodynamic changes with propofol, rise in heart rate after LMA insertion \& after 1 min were 6.8 \& $8.24 \%$ of preinduction values respectively. ${ }^{16}$ In Thiopentone group these values were $17.57 \%$ \& $26.23 \%$ above the preinduction level.

Rise in systolic blood pressure was $3.88 \%$ \& $4.8 \%$ after LMA insertion \& after $1 \mathrm{~min}$ in Propofol group. Whereas in group $\mathrm{T}$ this rise was $7.65 \%$ \& $12.23 \%$ above preinduction levels respectively.

Same pattern was followed by diastolic blood pressure in both the groups. These differences were statistically significant $(\mathrm{P}<0.05)$ in both the groups.

Haemodynamic parameters were highest after $1 \mathrm{~min}$ of LMA insertion \& after that gradually declined \& by 5 min they were near the preinduction values in propofol group $\&$ much higher than preinduction values in the Thiopentone group.

Three patients $(6 \%)$ regurgitated after removal of LMA, none of these aspirated. Two patients (4\%) had sore throat in the first 24 hours postoperatively. 


\section{CONCLUSION}

Propofol provides very good conditions for LMA insertion ${ }^{17-18}$ $\&$ it has been labelled as gold standard. Pressor response is present in both the groups, but it is much attenuated in Propofol group. LMA appears to be an excellent tool in armamentarium of anaesthesiologist and its routine use in certain situations should be encouraged.

\section{REFERENCES}

[1] Mason DG, Bingham RM. Forum: the LMA in children. Anaesthesia 1990;45:760-3.

[2] Molloy ME, Buggy DJ, Scanlon P. Propofol or sevoflurane for laryngeal mask airway insertion. Canadian Journal of Anaesthesia 1999;46(4):322-6.

[3] Ti LK, Chow MY, Lee TL. Comparison of sevoflurane with propofol for LMA insertion in adults. Anaesthesia \& Analgesia 1999;88(4):908-12.

[4] Hui JK, Critchley LA, Karmakar MK, et al. Coadministration of alfentanil - propofol improves laryngeal mask airway insertion compared to fentanyl -propofol. Canadian Journal of Anaesthesia 2002;49(5):508-12.

[5] Siddik-Sayyid SM, Aouad MT, Taha SK. A comparison of sevoflurane propofol versus sevoflurane or propofol for laryngeal mask insertion in adults. Anaesthesia \& Analgesia 2005;100(4):1204-9.

[6] Goh PK, Chiu CL, Wang CY, et al. Randomized doubleblind comparison of ketamine-propofol, fentanylpropofol, and propofol-saline on hemodynamic and LMA insertion conditions. Anaesthesia and Intensive Care 2005;33(2):223-8.

[7] Hannallah RS, Britton JT, Schafer PG, et al. Propofol anaesthesia in paediatric ambulatory patients: comparison with thiopentone and halothane. Canadian Journal of Anesthesia 1994;41(1):12-8.

[8] Yeo KS, Kua SW, Teoh GS, et al. The use of thiopentone/propofol admixture for LMA insertion. Anaesthesia \& Intensive Care 2001;29(1):38-42.

[9] Balk HJ, Kim JH, Lee CH. Laryngeal mask insertion during target controlled infusion of propofol. Journal of Clinical Anaesthesia 2001;13(3):175-81.
[10] Mottaghi K, Eftekharian A, Salimi A, et al. Comparison of post intubation complications of endotracheal tube \& LMA in paediatric patients. Annals of Anaesthesiology and Critical Care 2017;2(1):e10186.

[11] Bahk JH, Sung J, Jang IJ. A comparison of ketamine and lidocaine spray with propofol for the insertion of LMA in children - a double blinded randomized trial. Anaesthesia and Analgesia 2002;95(6):1586-9.

[12] Kashani S, Khosravi F, Jarineshin H. Hemodynamic responses to insertion of the LMA versus combitube. Homozgan Medical Journal 2017;20(6):345-54.

[13] Sivalaingum P, Kandasamy R, Madhavan G, et al. Conditions for LMA insertion - a comparison of propofol versus sevoflurane with or without alfentanyl. Anaesthesia 1997;54:271-6.

[14] Khot A, Jamale TB, Dhulkhed VK, et al. Controlled study of comparison of intraocular pressure and hemodynamic responses to insertion of the I-gel. Classical LMA and endotracheal tube. Journal of Evolution of Medical and Dental Sciences 2016.

[15] Park HJ, Lee JR, Kim CS, et al. Remifentanyl halves the EC50 of propofol for successful insertion of the LMA and laryngeal tube in paediatric patients. Anaesthesia \& Analgesia 2007;105(1):57-61.

[16] Kushwaha R, Choudhary S. A comparative study between propofol and thiopentone for hemodynamic parameters during induction of general anaesthesia in surgical patients. J Med Allied Sciences 2017;7(1):913.

[17] Balk HJ, Kim YJ, Kim JH. Lidocaine given intravenously improves conditions for LMA insertion during propofol target-controlled infusion. European Journal of Anaesthsia 2009;26(5):377-81.

[18] Chia YY, Lee SW, Liu K. Propofol causes less postoperative pharangeal morbidity than thiopental after the use of a laryngeal mask airway. Anaesthesia \& Analgesia 2008;106(1):123-6. 